\title{
The Optimal Number of Firms with an Application to Professional Sports Leagues
}

By

\author{
SangHoo Bae* and Jay Pil Choi**
}

\begin{abstract}
This paper analyzes a cartel's optimal choice of the number of firms in Salop's (1979) circular city model under different assumptions about cooperative behaviors among firms. We consider two scenarios: (1) a cartel operates under a fully collusive regime in which it controls the number of firms and their pricing, and (2) a cartel operates under a semi-collusive regime in which it controls only the number of firms and pricing is left to individual firms. We compare the outcomes in both scenarios to the socially optimal and free entry outcomes. We then apply these comparisons to the case of a professional sports league's optimal choice of the number of franchises.
\end{abstract}

JEL Classification: D4, L1, L83

Keywords: professional sports leagues, circular city.

\author{
*SangHoo Bae \\ Department of Economics, Clark University \\ Worcester, MA 01610 \\ E-mail: sbae@clarku.edu \\ **Jay Pil Choi \\ Department of Economics, Michigan State University \\ East Lansing, MI 48824 \\ E-mail: choijay@msu.edu
}

We thank Carl Davidson and Thomas Jeitschko for useful comments and encouragement. We also thank two anonymous referees and Editor for providing very helpful and constructive comments that greatly improved the exposition of the paper. 


\section{Introduction}

Contracting in Major League Baseball (MLB), which is delayed until 2006 as the outcome of the collective bargaining agreement between MLB players and owners in 2002, still remains a controversial issue. Unlike other industries in which it is unlawful for competing firms to determine which firms should exit or the number of firms in an industry, the contracting argument may reveal one of the distinctive characteristics of professional sports league: industry-wide cooperative behaviors among teams with some degree of antitrust exemption. ${ }^{1}$

This paper constructs a model regarding a cartel's optimal choice of the number of firms and their pricing under different degree of cooperative behaviors among firms. We then relate the equilibrium and optimal number of firms to a professional sports league's choice of the number of franchises and ticket pricing. Parallel with the notion of a cartel which is an association of firms that explicitly coordinates its pricing or output activities, we assume a professional sports league as the cartel which coordinates the number of teams and possibly ticket pricing. ${ }^{2}$

We distinguish between two types of cartels characterized by their degree of control over member firm's pricing behavior and show that the optimal number of firms depends crucially on the nature of the cartel. We first assume that there is a cartel with full collusion which has absolute control over the number of firms as well as their pricing. Even without direct control over price, for example, a cartel may control its members' prices through other mechanisms such as an exclusive territory. In the case of professional sports industry, an exclusive territorial franchise is assigned to the owner of

\footnotetext{
${ }^{1}$ For instance, Major League Baseball enjoys an absolute exemption from all federal antitrust laws. Other sports leagues also enjoy various degrees of antitrust exemption such as the ability to negotiate league-wide broadcast rights. See Leeds and Allmen (2004) for details.

${ }^{2}$ In the case of the Korea Baseball Organization (KBO) the ticket price was set by the league until 2002. However, in the beginning of the 2003 season, each franchise was able to determine own ticket price schedule.
} 
each member team in a league. ${ }^{3}$ In this case, a cartel with full collusion is able to determine the number of firms and enforce firms not to undercut its price. The second type of cartel we consider is a semi-collusive cartel which controls the number of member firms, but pricing is independently determined by each firm in non-cooperative behavior.

To analyze a cartel's optimal choice of the number of firms, we adopt the Salop's (1979) circular city model, and we investigate how the degree of control over member firms determines the cartel's optimal choice. Depending on the degree of control, the cartel is shown to choose a different number of firms. We compare the outcomes to the socially optimal and free entry ones. More specifically, under full collusion with the ability to control industry-wide pricing behavior, the cartel selects the number of firms with consideration of a trade-off between the reduction of distance cost of marginal consumers and the increase in fixed cost when the cartel decides to add an additional member firm. On the other hand, if the cartel is not able to prevent member firms to cut their prices below the collusive level, each member has an incentive to deviate when the number of firms is set at the fully collusive level. As the member firms sell products at the lower price to inframarginal consumers to increase sales, the joint profits for the cartel will be reduced. This incentive to cut prices induces the semi-collusive cartel to choose a smaller number of firms until each member becomes a local monopoly.

Previous papers concerned with the optimal choice of number of franchises in professional sports leagues include Vrooman (1997b), Fort and Quirk (1995) and Kahn (2003) among others. Vrooman (1997b) analyzes the optimal size of a league explicitly by analogy with Buchanan's (1965) theory of clubs. He shows that if each franchise has an interest in maximizing the league's total revenue, franchises should expand to the point at which average revenue of franchises is maximized. Also, the optimal number of

\footnotetext{
${ }^{3}$ In the National Football League (NFL), for example, a team's territory is within a seventy-five-mile radius of the team's home field.
} 
franchises is smaller than the socially optimal choice which maximizes total franchises revenue. This paper, in contrast, allows two different types of cartel according to the control over franchises and compares the outcomes in both scenarios to the socially optimal and free entry outcomes. ${ }^{4}$

Fort and Quirk (1995) also provide historical evidence of the league's expansion choices with the threat of entry of a new league. However, there is no theoretical framework to explain the mechanism of the expansion choice or the optimal choice of the league. This paper is able to provide such a theoretical framework by adopting the Salop's circular city model.

Finally, in a recent paper Kahn (2003) addresses the same question of optimal sport league size. However, his approach is very different from ours in that the main determinant in his analysis is the quality of players. In addition, he uses national television contracts as the major source of revenue whereas we focus on ticket pricing. As such, Kahn's (2003) study can be viewed as complementary to ours, focusing on different aspects of the same issue.

The remainder of this paper is organized as follows. Section 2 sets up the basic model and analyzes the two-stage game of the fully-collusive and semi-collusive cartel, in which the optimal number of firms is determined. We compare this number with the socially optimal one and the one that would prevail under the condition of free entry. We then apply these comparisons to the case of a professional sports league. Section 3 contains concluding remarks.

\section{The Optimal Number of Franchises}

To examine the cartel's entry decision with differentiated products, we use the circular city model a' la Salop (1979). Consumers are located uniformly on a circle with a

\footnotetext{
${ }^{4}$ Cyrenne (2001), as in our paper, compares the non-cooperative outcome to the socially optimal one. However, he compares the optimal number of games in a season, not the optimal number of franchises.
} 
perimeter equal to 1 . Firms are located equidistant from each other, that is, if there are $n$ firms, the distance between firms is $1 / n$. In the case of a sports league the location of consumers in the circular city model represents their fan loyalties for an ideal team. Consumers are assumed to suffer disutility from choosing a variant that differs from their ideal. Fans want to buy one unit of the good, such as a seasonal ticket, and have a cost per unit of distance $t$. Their reservation value for the ticket of their ideal team is given by $v$. Consumers will buy a ticket from the team that offers the lowest generalized cost (ticket price + transportation cost) if it does not exceed their reservation value.

To analyze the issue of the number of firms, we assume that there is a fixed cost $F$ when a firm decides to enter the market. In addition, each firm faces an identical marginal cost $c$ of serving consumers. Therefore, firm $i$ 's profit is $\left(p_{i}-c\right) q_{i}-F$ if it enters and sells to $q_{i}$ consumers at the price of $p_{i}$, and 0 otherwise.

To facilitate the analysis below, we first consider the optimal pricing problem for a local monopoly that does not face any competition as a benchmark. ${ }^{5}$ If a monopolistic firm charges a price of $p^{m}$, the marginal consumers who are indifferent between buying and not buying a product are located at the distance $\tilde{x}^{m}=(v-p) / t$ away from the firm. Thus, the demand for the local monopoly is given by $2 \widetilde{x}^{m}=2(v-p) / t$. This implies that the monopolistic firm sets the price as $p^{m}=\frac{v+c}{2}$. The demand faced by the monopoly is given by $q^{m}=\frac{v-c}{t}$ if $v<c+t$ and its profits are $\pi^{m}=\frac{(v-c)^{2}}{2 t}-F$. To have a meaningful analysis, we need to make the following assumption to ensure that the local monopoly is profitable.

Assumption 1. $v-c>\sqrt{2 t F}$

We now analyze two cases depending on the degree of the cartel's control over the conduct of member firms.

\footnotetext{
${ }^{5}$ The analysis here corresponds to the case of "monopoly" region in Salop's (1979) analysis.
} 


\section{Cartel with Full Collusion}

Consider a situation where the cartel has complete control over its member, that is, the cartel chooses the number of firms in the first stage and firms coordinate their prices to maximize their joint profits in the second stage. For analytical simplicity, we ignore the integer constraint and treat the number of firms $(n)$ as a continuous variable. With the assumption of continuous $n$ and assumption 1, it is obvious that the whole market will be covered in the case of full collusion.

Lemma 1. A critical consumer who is indifferent between purchasing from firm $i$ and purchasing from firm $i$ 's closest neighbor does not get any consumer surplus.

Proof. Suppose not. Then, the cartel can increase the prices of both firms by the amount of the critical consumer's surplus and can increase the total profit since there will be no change in the amount of demand for both firms.

With the help of Lemma 1, we can easily calculate the optimal number of firms for the fully collusive case. We proceed by backward induction. In the second stage without a threat of price cut by its neighbor firms, each member charges the maximum price given the market shares. Firm $i$ sets its price such that an indifferent consumer, who is denoted by $\tilde{x}_{i}^{c}=\frac{v-p_{i}^{c}}{t}$, is located at the end of his territory. Price and demand for firm $i$ then are given by

$$
p_{i}^{c}=v-\frac{t}{2 n^{c}} \text { and } q_{i}^{c}=2 \widetilde{x}_{i}^{c}=\frac{1}{n^{c}} .
$$

Profits of firm $i$ are given by $\pi_{i}^{c}=\left(p_{i}^{c}-c\right) q_{i}^{c}-F=\left(v-\frac{t}{2 n^{c}}-c\right) \frac{1}{n^{c}}-F$. Once firms choose their collusive price in the second stage, the cartel selects the optimal number of firms. The fully collusive cartel chooses $n^{c}$ such that 


$$
\underset{n^{c}}{\operatorname{Max}} n^{c} \pi_{i}^{c}=n^{c}\left[\left(v-\frac{t}{2 n^{c}}-c\right) \frac{1}{n^{c}}-F\right] .
$$

Thus, the optimal number of firms for the cartel with full collusion is $n^{c}=\sqrt{\frac{t}{2 F}}$.

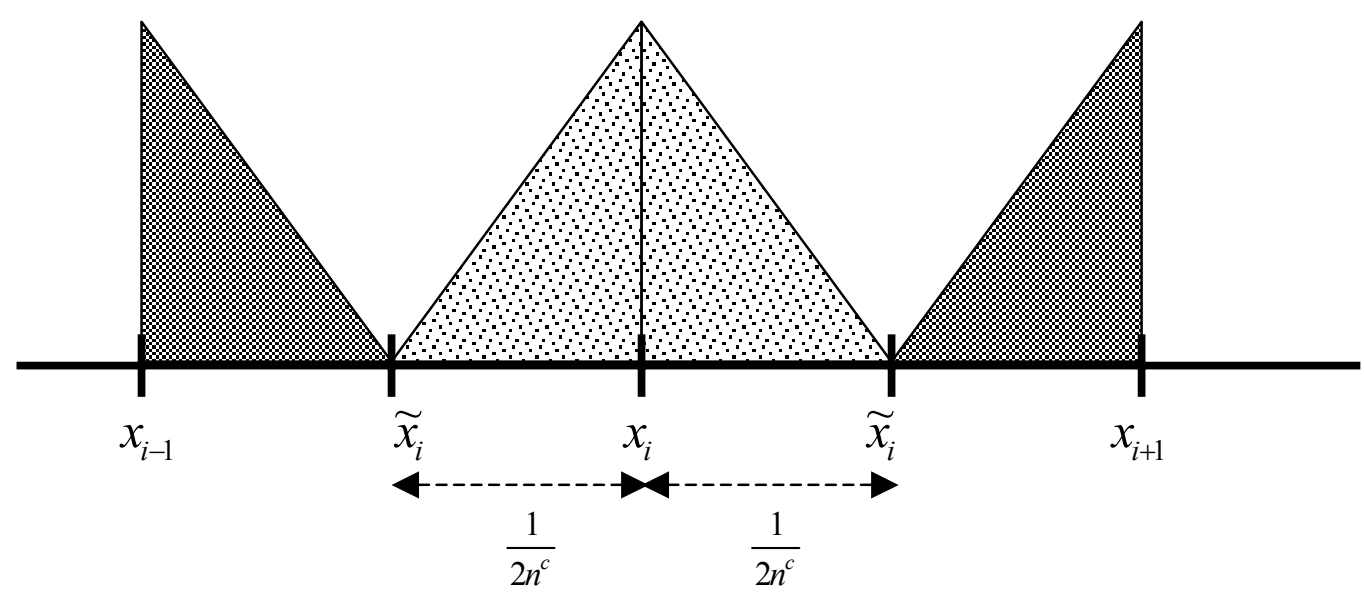

Figure 1. the critical consumers in the case of the cartel with full collusion

\section{Semi-Collusive Cartel without Price Control}

We now consider a semi-collusive cartel that does not have complete control over member firms' pricing behavior. It is only capable of choosing the optimal number of firms in the first stage. By considering the second stage first, given the number of firms, $n^{s c}$, each firm faces demand of $q_{i}^{s c}=\frac{1}{t}\left(p_{j}^{s c}+\frac{t}{n^{i c}}-p_{i}^{s c}\right)$ and profits of firm $i$ are given by

$$
\pi_{i}^{s c}=\left(p_{i}^{s c}-c\right) q_{i}^{s c}-F=\left(p_{i}^{s c}-c\right) \frac{1}{t}\left(p_{j}^{s c}+\frac{t}{n^{s c}}-p_{i}^{s c}\right)-F .^{6}
$$

Therefore, each firm sets its price as $p^{s c}=c+\frac{t}{n^{s c}} .^{7}$ In the first stage, the semi-collusive cartel should choose the optimal of number of firms, $n^{s c}$, so that it maximizes its joint profits, where the joint profits are given by $\Pi^{s c}=n \pi_{i}^{s c}=\frac{1}{n^{s c}}-n^{s c} F$. The first order condition with respect to $n^{s c}$, however, is negative for all positive $n^{s c}$, implying that reducing the number of firms increases the joint profits. There are two reasons for this; it

${ }^{6} n^{s c}$ denotes the number of firms in a semi-collusive cartel case.

${ }^{7}$ The only equilibrium in this model is symmetric. 
alleviates price competition among firms and reduces the aggregate fixed costs at the same time. This means that the semi-collusive cartel is able to increase joint profits by reducing the number of firms. We thus conclude that the semi-collusive cartel increases the distance between firms by choosing a smaller number of firms until each member becomes a local monopoly. More precisely, the semi-collusive cartel chooses the optimal number of firms as $\frac{1}{n^{s c}}=q^{m}=\frac{v-c}{t}$; the optimal number of firms for the semi-collusive cartel is $n^{s c}=\frac{t}{v-c} .8$

Under assumption 1, we have $n^{c}=\sqrt{\frac{t}{2 F}}=\frac{t}{\sqrt{2 t F}}>\frac{t}{v-c}=n^{s c}$. Thus, we have the following proposition.

Proposition 1. Without control over member firm's pricing behavior, the semi-collusive cartel chooses a smaller number of firms than the fully collusive cartel with price control $\left(n^{s c}<n^{c}\right)$.

The intuition for Proposition 1 can be explained in the following way. Each firm's pricing decision is constrained by either the competition margin or the reservation value margin. ${ }^{9}$ That is, the marginal consumers for each firm are those who are indifferent between purchasing from it or purchasing from its neighbor (competitive margin binding) or those who are indifferent between purchasing from it or not purchasing (reservation margin binding). If there are more member firms than the optimal number $\left(n^{s c}\right)$ in the semi-collusive cartel case, the binding constraint is the competitive margin. In such a case, reducing the number of firms relaxes price competition and saves on fixed costs without affecting the reservation value margin. The

\footnotetext{
${ }^{8}$ In this case the semi-collusive league cartel fills the market without market gap. With the assumption of continuous $n$, it is never optimal to leave a gap in the market.

${ }^{9}$ In Salop's (1979) terminology, the representative firm is operating in the "competitive" region if the competitive margin is binding and it is operating in the "monopoly" region if the reservation value margin is binding.
} 
semi-collusive cartel will reduce the number of firms until the competition margin is not binding. With the optimal number of firms $\left(n^{s c}\right)$, the competition margin is not binding and the only binding constraint is the reservation value margin, which implies that every member firm is a local monopoly. Under the fully collusive cartel regime, the league is never bound by the competition margin and does not need to reduce the number of franchises to relax competition between firms. ${ }^{10}$

\section{Free entry}

Now we consider free entry case in which there is no entry barrier except fixed costs. Thus any potential firm enters the market whenever its profits are greater than fixed costs. A two-stage game is considered. In the first stage, potential franchises simultaneously choose whether or not to enter. As in Salop's model, we assume that franchises do not choose their locations, but they are located the same distance from each other. Moreover, each firm's choice of price and quantity in the second stage is identical to the case of the semi-collusive cartel. In the first stage, potential firms enter the market until $\pi_{i}^{f}=\left(p_{i}^{f}-c\right) \frac{1}{n^{f}}-F=0$. The equilibrium number of firms with free entry is $n^{f}=\sqrt{\frac{t}{F}} \cdot 11$

\footnotetext{
${ }^{10}$ One of the referees provides an alternative explanation; at the equilibrium, only the reservation margin is binding in both the fully collusive and the semi-collusive cases. In the semi-collusive case, each firm chooses the monopoly price with corresponding demand $q^{m}$, and then the cartel locates member firms so that they are $q^{m} / 2$ apart. In the case of the fully collusive case, suppose the league raises all firms' prices slightly and increases the number of firms such that the reservation margin continues to bind. The profit per member firm is roughly unchanged, but there is a first-order increase in profit from the greater number of firms.

${ }^{11} n{ }^{f}$ denotes the number of firms with free entry.
} 


\section{Social Optimum}

When there are $n^{s}$ firms at distance of $\frac{1}{n^{s}}$ apart from its neighboring firms and they all sell products at a price of $p^{s}$, total surplus generated by firm $i$ is

$s\left(n^{s}\right)=2 \int_{0}^{\frac{1}{2 n^{s}}}\left(v-p_{i}^{s}-t x\right) d x+\frac{p_{i}^{s}}{n^{s}}-\frac{c}{n^{s}}-F=\frac{v}{n^{s}}-\frac{p_{i}^{s}}{n^{s}}-t\left(\frac{1}{2 n^{s}}\right)^{2}+\frac{p_{i}^{s}}{n^{s}}-\frac{c}{n^{s}}-F$

From the above total surplus of one firm, we have the total surplus in a $n^{s}$-firm market as $S\left(n^{s}\right)=n^{s} s\left(n^{s}\right)=v-\frac{t}{4 n^{s}}-c-n^{s} F$. Maximization with respect to $n^{s}$ yields the socially optimal number of firms, $n^{s}=\sqrt{\frac{t}{4 F}}$.

\section{Comparison}

We now compare the optimal number of firms under different regimes to the socially optimal one and the one that prevails under free entry condition.

Proposition 2. With complete control over pricing behavior of member firms, the cartel is made up of a larger number of firms than the socially optimal one, but a smaller number of firms than the free entry one $\left(n^{s}<n^{c}<n^{f}\right)$.

Proof. A simple comparison of expressions for $n^{s}=\sqrt{\frac{t}{4 F}}, n^{c}=\sqrt{\frac{t}{2 F}}$, and $n^{f}=\sqrt{\frac{t}{F}}$.

The discrepancy in choices between the fully collusive league cartel and that of the social planner can be explained by Spence's (1975) intuition for the monopolistic provision of quality, if we interpret the number of firms as quality since more firms imply a better match between preferences of consumers and firm locations. As Spence (1975, 1976) has pointed out, the fully collusive cartel's incentive to establish an additional firm is related to the marginal increase in gross utility for the marginal consumer whereas the social planner's incentive depends on the marginal increase in gross utility for the 
average. In our model, the marginal consumers gain more than the average consumer in gross utilities as the number of firms increases. More specifically, by increasing the number of firms by $\Delta n$, the marginal consumer's transportation cost decreases by $\frac{d(t / 2 n)}{d n}=-\frac{t}{2 n^{2}}$. The average transportation cost is given by $\frac{1}{2 n} \cdot \int_{0}^{\frac{t}{2 n}} t x d x=\frac{t}{4 n}$, which implies that the average consumer's transportation cost decreases by $\frac{d(t / 4 n)}{d n}=-\frac{t}{4 n^{2}}$. Thus, the marginal impact of increasing the number of firms on gross utility is greater for the marginal consumer than the average consumer. As a result, the fully collusive cartel is made up of more firms than the socially optimal level.

When the cartel is semi-collusive and does not have control over member firms' pricing, we know that it establishes fewer firms than the fully collusive cartel to eliminate price competition among member firms. However, the number of firms can be either larger or smaller than the socially optimal choice [see figure 2].

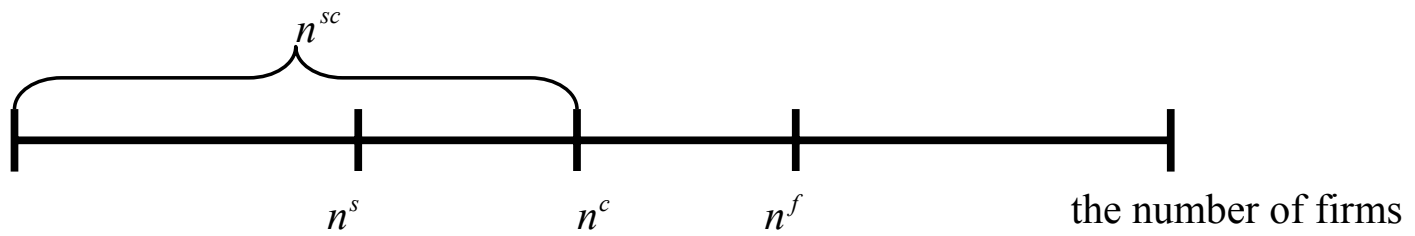

Figure 2. comparison of the number of firms under different regimes

Proposition 3. The comparison between the number of firms under a semi-collusive cartel $\left(n^{s c}\right)$ and the socially optimal one $\left(n^{s}\right)$ depends on parameter values. If $v-c>\sqrt{4 t F}, n^{s}>n^{s c}$. Otherwise, $n^{s}<n^{s c}$.

Proof. A simple comparison of expressions for $n^{s}$ and $n^{s c}$ proves the proposition.

A corollary of Proposition 3 is that if $v-c<\sqrt{4 t F}$, it would be welfare improving not to allow price coordination for the cartel since $n^{s}<n^{s c}<n^{c}$; such a policy would induce the 
cartel to choose the number of firms more aligned with the socially optimal one. If $v-c>\sqrt{4 t F}$, however, such a policy would overshoot the target $\left(n^{s}\right)$ and its welfare implication is ambiguous.

We now go back to the issue of contraction in Major League Baseball. Based on Proposition 3 we may argue that the effect of contraction in MLB is ambiguous since all four major professional sports leagues in the U.S. operate as a semi-collusive cartel. It would be welfare improving if $v-c<\sqrt{4 t F}$, so that the number of franchises becomes closer to the socially optimal one. Otherwise, having fewer franchises in the league decreases social welfare since we have $n^{s}>n^{s c}$ with the range of parameter values of $v-c>\sqrt{4 t F}$.

\section{Concluding Remarks}

In this paper we develop a simple model of the choice of a cartel about the number of member firms. We examine the optimal choice of the cartel with various degrees of control over firm's pricing behaviors and compare them with the socially optimal one and the one under free entry based on Salop's circular city model. We conclude that the semi-collusive cartel provides a smaller number of firms than the fully collusive cartel. Since the semi-collusive league cartel cannot control prices, it chooses a smaller number of firms to relax price competition. Second, the fully collusive cartel chooses a larger number of firms compared to the socially optimal one. The cartel's choice is based on the difference between the surplus of the marginal consumer and the fixed cost. On the other hand, the social planner's choice is based on the average surplus of consumers. This leads to the league's overprovision in the variety of firms to maximize its joint profits. Therefore, the effectiveness of policy towards the sports leagues should be evaluated with more caution. 


\section{References}

Buchanan, J., “An Economic Theory of Clubs,” Economica, 1965, pp. 1-14.

Cyrenne, P., “A Quality-of-Play Model of a Professional Sports League,” Economic Inquiry, 2001, 39, pp. 444-452.

Fort, R. and Quirk, J., 'Cross subsidization, Incentives and Outcomes in Professional Team Sports Leagues,” Journal of Economic Literature, 1995, 33, pp. 1265-1299.

Kahn L., "Sports League Expansion and Economic Efficiency: Monopoly Can Enhance Consumer Welfare,” CESifo Working Paper No. 1101, 2003.

Leeds, M. and Allmen, P., The Economics of Sports (Boston, MA: Addison Wesley, 2004)

Salop, S, "Monopolistic Competition with Outside Goods," Bell Journal of Economics, 1979, 10, pp. 141-156.

Spence, A.M., “Monopoly, Quality, and Regulation,” Bell Journal of Economics, 1975, 6, pp. 417-429.

Spence, A.M., "Product Selection, Fixed Costs and Monopolistic Competition," Review of Economic Studies, 1976, 43, pp. 217-235.

Vrooman, J., "Franchise Free Agency in Professional Sports Leagues," Southern Economic Journal, 1997b, July, pp. 191-219. 